\title{
MANUAL DE FONTES DE INFORMAÇÃO
}

CUNHA, Murilo Bastos da. Manual de fontes de informação. Brasília, DF: Briquet de Lemos, 2010. 182p. ISBN 9788585637422.

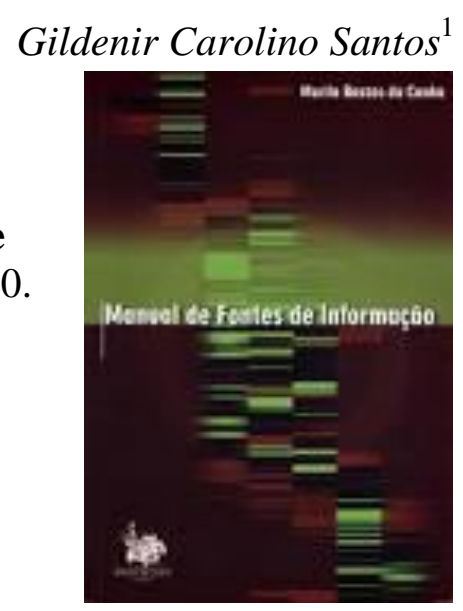

Recomendar a leitura e uso de uma obra escrita por um autor e professor renomado para o público brasileiro pode ser facilmente justificável pela qualidade já consagrada de sua produção bibliográfica.

O professor Murilo Bastos da Cunha propõe com esse livro uma apresentação concisa das principais obras de referência utilizadas praticamente por todos os profissionais, alunos e professores de diversas áreas. "Aqui, como é assinalado no prefácio de Paulo da Terra Caldeira, o autor apresenta um 'espectro mais amplo' do que aquele tentado pelos antecessores brasileiros 'abrangendo tipos de materiais indispensáveis para consulta no cotidiano da população' que 'facilitam a identificação e o conhecimento de enorme número de fontes e mecanismos para recuperação de informação em meio eletrônico'.” (p.ix).

O autor é bibliotecário e professor da Universidade de Brasília. Murilo Bastos da Cunha é doutor em Ciência da Informação pela University of Michigan, onde fez também seu pós-doutorado. É bacharel em Biblioteconomia pela Universidade de

\footnotetext{
${ }^{1}$ Resenhista da obra citada em questão. Bibliotecário graduado pela PUC-Campinas. Diretor Técnico da Biblioteca - Faculdade de Educação UNICAMP; Mestre e Doutor em Educação pela Faculdade de Educação/ UNICAMP; Pós-doutor pelo Labjor/UNICAMP. Campinas, SP, Brasil. E-mail: gilbfe@unicamp.br

Enviado em: 01/11/2012 - Aceito em: 05/12/2012.
} 
Brasília com especialização em Biblioteconomia em Minas e Energia e mestre em Administração de Bibliotecas pela Universidade Federal de Minas Gerais.

Nessa obra são citadas 480 fontes impressas e digitais, em sua maioria, de língua portuguesa. Também são citadas fontes estrangeiras, "quando disponíveis e apropriadas para o contexto brasileiro.” (p.xi).

$\mathrm{O}$ autor comenta que:

\begin{abstract}
Esta obra não é exaustiva. Os registros incluídos foram os que obtiveram aprovação no requisito de relevância para o usuário brasileiro. É preciso ressaltar que mesmo as bases de dados e outras fontes digitais de referência passam por constantes mudanças. Hoje é cada vez mais comum as editoras anunciarem o reempacotamento de seus produtos quando comercializados por diferentes distribuidores de informação digital. Esses produtos informacionais são personalizados (ou 'customizados') para atender a determinados nichos de mercado. Portanto, é possível haver o mesmo produto licenciado para diferentes vendedores e então reformatados para atender a um tipo de clientela. Esta fluidez da informação digital e sua veiculação, geralmente na internet, acarretam enormes desafios para quem procura elaborar um guia bibliográfico. (p.xi)
\end{abstract}

A obra foi impressa em outubro de 2010, possui 182 páginas e está dividida em 7 (sete) capítulos, e no final possui um índice remissivo de autores e dos tipos de fontes de informação, em cada capítulo existe uma lista de bibliográfica de leituras complementares referente a fonte de informação em questão.

No primeiro capítulo o autor discorre sobre as Enciclopédias apontando seu significado no idioma grego, bem como o objetivo específico, definindo como uma obra essencial ao acervo de qualquer biblioteca. Apresenta as principais funções das enciclopédias, resumindo que podem ser consideradas "como a mais importante das obras de referência". O autor ainda comenta que em tempos de Wikipédia e Google, enganam-se aqueles que pensam que as enciclopédias podem ser extintas, pois muito pelo contrário "as vendas no formato tradicional ainda são expressivas". (p.4). O autor inicia com as principais enciclopédias em língua portuguesa fazendo uma descrição analítica de cada uma delas, em seguida são descritas as enciclopédias de outras línguas como alemão, espanhol, francês, inglês e italiano. $\mathrm{O}$ autor baseado em alguns autores (Bopp \& Smith; Katz; Martin Vega; Melnik e Silberger) apresenta um estudo de como avaliar uma enciclopédia, e finaliza disponibilizando 15 (quinze) bibliografias para leituras complementares.

O segundo capítulo o autor reserva para os Dicionários, considerados uma “obra de referência que dá informações sobre as palavras e sua grafia, pronúncia, 
significado, etimologia, sinonímia e antonímia." (p.19). Além desses itens, o autor aponta que o dicionário propõe-nos a dar respostas como definições, plural, etimologia, sinônimo e regionalismo. Ainda neste capítulo, são apresentadas as características dos dicionários, as funções e os tipos de arranjos. A tipologia dos dicionários, segundo o autor pode ser classificados como gerais e especializados. Em seguida o autor descreve analiticamente os dicionários em língua portuguesa nos formatos impressos e eletrônicos, os de língua portuguesa para crianças e escolares, seguidos pelos dicionários em outras línguas (01 - árabe, 1 - búlgaro, 3 - chinês, 9 espanhol, 7 - francês, 3 - grego, 2 - guarani, 5 - hebraico, 10 - inglês, 6 - italiano, 6 japonês, 11 - latim, 2 - neerlandês, 1 - polonês, 1 - romeno, 5 - russo, 1 servo-croata, 1 - sueco. $\mathrm{O}$ autor destaca 11 (onze) dicionários disponibilizados gratuitamente na internet, sendo a maioria de língua inglesa, informa o site de acesso e suas descrições. Assim como as enciclopedias, Murilo Bastos da Cunha apresenta critérios, segundo autores citados anteriormente (Bopp \& Smith; Katz; Martin Vega; Melnik e Silberger) de como avaliar dicionários. Finaliza com a indicação de 15 (quinze) obras para leituras complementares.

As Fontes biográficas compõe o terceiro capítulo. Como ele mesmo comenta, “as fontes biográficas podem apresentar biografias de várias personalidades". (p.63). Essas fontes biográficas "podem ter um escopo universal ou certas limitações, como por exemplo, geográficas, contendo biografias de personalidades de certa localidade, ou incluir somente dados sobre pessoas falecidas, ou mesmo especialistas de um único grupo profissional, como também somente pessoas vivas.” (p.64). O autor destaca que essas fontes "basicamente se dividem em duas classes: os dicionários biográficos, que se encarregam de recolher dados sobre pessoas do passado, e os diretórios, que se ocupam da informação relativa às pessoas do presente.” (p.64). Segundo vários critérios descritos pelo autor, essas fontes biográficas podem ser classificadas como: atividades do biografado; nacionalidade do biografado; período de cobertura das biografias; forma de arranjo das biografias. Menciona ainda neste Manual de Fontes de Informação a existência de outros tipos de documentos, também denominados de literatura pessoal como: autobiografia; diários; epistolários e memórias. Nesse contexto, o autor cita cinco principais fontes de informação biográfica: 1) enciclopédia, 2) dicionário biográfico, 3) diretório ou cadastro, 4) 
periódico, 5) entidades especializadas. Ele explica ainda nesse Manual que as fontes existentes na internet são comentadas dentro de cada uma das fontes citadas anteriormente. Faz uma descrição analítica de cada uma delas, sendo 3 (três) enciclopédias; 18 (dezoito) dicionários biográficos; 22 (vinte e dois) diretórios biográficos; 05 (cinco) periódicos; 3 (três) entidades especializadas, a maioria deles na língua portuguesa, também são citadas fontes de outros países. São apresentados os critérios de como avaliar essas fontes biográficas, finalizando o capítulo com a indicação de 15 (quinze) obras para leituras complementares sobre o assunto.

O quarto capítulo refere-se às Fontes geográficas, o autor apresenta os mapas, enciclopédias e dicionários geográficos, guias de viagens e outras fontes importantes para a recuperação da informação geográfica. Ele relata de forma hsitórica essas fontes, no caso dos mapas, mencionando-os no mundo e no Brasil. Destacando o mapa do ponto de vista cartográfico, "é uma representação convencional da Terra em uma superfície plana, em escala reduzida." Apropria-se de outros conceitos dados aos mapas, como carta geográfica, atlas geográfico ou simplesmente atlas. São apresentados 7 (sete) atlas brasileiros para o público em geral, e 14 (quatorze) atlas para estudantes, sendo 9 (nove) brasileiros e 5 (cinco) de outros países. Já os atlas históricos são referenciados analiticamente 3 (três) em português e 4 (quatro) de outros países. O autor comenta que para se encontrar "os dados básicos sobre latitude e longitude de um lugar ou acidente geográfico geralmente são encontrados nos índices dos atlas." (p.91) Entretanto, salienta que, "outros tipos de dados podem ser necessários e, para isto, é importante consultar um dicionário geográfico" (p.91), ou até mesmo uma enciclopédia geográfica. Na língua portuguesa são referenciados analiticamente 8 (oito) fontes, e em outras línguas 3 (três). Os guias e portais de viagem, que trazem informações sobre hotéis, restaurantes, pontos de interesse, passaporte, visto consular, aluguel de carro e câmbio, são fontes regularmente publicadas no formato impresso, mas também podem ser encontrados na internet. $\mathrm{O}$ autor referencia de forma análitica 8 (oito) fontes com foco nos guias, sítios e portais turísticos e rodoviários na língua portuguesa, e em outras línguas são mencionados 6 (seis). Os periódicos sobre viagens e turismo são descritos em 3 (três) fontes. Nas fontes da internet são referenciadas analiticamente 25 (vinte e cinco) fontes em português, sendo a maioria citadas na língua inglesa. Como outras fontes importantes, 
são referenciadas 2 (duas) obras do IBGE uma no formato impresso e a outra no formato web. O capítulo descreve a forma como avaliar as fontes geográficas, além da indicação de 26 (vinte e seis) obras para leituras complementares.

O quinto capítulo destaca as Fontes estatísticas que são definidas pelo autor como "um conjunto de métodos e processos quantitativos que serve para estudar e medir os fenômenos coletivos." (p.106), ou seja, o fenômeno coletivo é aquele que se refere à população. Os dados estatísticos podem ser classificados sob três pontos de vista: origem dos dados; abrangência geográfica e dados coletados. Ele menciona que as consultas sobre dados estatísticos são comuns no serviço de referência de uma biblioteca. Além disso, justifica que "no mundo atual os dados estatísticos são imprescindíveis a quase todas as atividades científicas e profissionais.” (p.109). As principais fontes estatísticas são as instituições, pois elas coletam, processam, analisam e difundem dados estatísticos. $\mathrm{O}$ autor referencia analiticamente 13 (treze) instituições estrangeiras de interesse para os assuntos brasileiros, e 8 (oito) instituições brasileiras. Na sequência são citadas as 12 (doze) bases e bancos de dados de estatística nacional e estrangeira, 12 (doze) anuários estatísticos e 5 (cinco) diconários e enciclopédias de estatística. Traz também procedimentos de como avaliar as fontes estatísticas e finaliza este capítulo com 10 (dez) obras para leituras complementares.

No sexto capítulo são apresentadas as Fontes jurídicas, tendo em vista que existem diversas fontes jurídicas no contexto da recuperação da informação, sendo que as principais são: legislação, jurisprudência e doutrina. Nesse sentido, o autor apresenta as fontes de informação jurídica, tendo as bibliografias brasileiras as mais atuantes, como a Bibliografia Brasileira de Direito e a Bibliografia da Justiça Federal. $\mathrm{Na}$ sequência são apresentas 15 (quinze) enciclopédias e dicionários brasileiros no formato impresso, e 6 (seis) enciclopédias e dicionários também brasileiros, no formato eletrônico. Continuando as descrições das fontes jurídicas, o autor apresenta 16 (dezesseis) bases, bancos de dados e portais de acesso público, e 18 (dezoito) bases, bancos de dados e portais de acesso privado, ambos de língua portuguesa. Nos códigos, ou seja, "reunião de obras ou documentos organizados de modo a facilitar o manuseio, com o objetivo principalmente de aperfeiçoar tempo e espaço" (p.140), e os vade-mécuns, expressão em latim que significa 'vai comigo',“funciona também 
como espécie de código que reúne várias normas legais” (p.140) que reúne 4 (quatro) bibliografias descritas analiticamente no formato impresso. Também estão reunidos as 9 (nove) fontes juridícas no suporte como periódicos de legislação. Outras fontes jurídicas são os mecanismos de busca e diretórios que estão listadas três mecanismos de origem brasileira. Finalizando este capítulo são apresentados os procedimentos de como avaliar as fontes jurídicas, e 12 (doze) obras para leituras complementares.

O sétimo e último capítulo destaca os Serviços de busca. Neste capítulo é enfocada a internet, que tem sua origem iniciada nos finais dos anos 1960, passando para o surgimento do World Wide Web, ou WWW, ou simplesmente web, e do primeiro programa de navegação, ocorridos a partir de 1992. O autor retrata em sua obra as esferas ou componentes mais importantes da internet, tais como: web; e-mail; FTP; WAIS e o Gopher. Aqui são mencionados os tipos de serviços de busca, ou seja, "sítios especializados em localizar informações na internet." (p.154). O autor comenta que estes serviços de busca são divididos em três categorias, diferenciando-se da indexação e armazenagem de seus bancos de dados. Entre estas fontes sobre serviços de busca estão: os diretórios ou repertórios de assuntos (Yahoo; Google Diretory; About.com), o mecanismo de busca (Google; Ask; Bing) e o metamecanismo de busca (WebFerrey; Mata Hari; Copernic). Estão relacionados aqui 9 (nove) manuais na língua portugues e inglesa; $10(\mathrm{dez})$ documentos na web. Dos principais serviços de busca, são citados os serviços do Yahoo (1994), o espanhol Buscopio, uma "base de dados sobre serviços de busca, onde são indexadas centenas, demonstrando, assim, que é uma área de grande crescimento.” (p.159). O autor relata nesta obra, as estratégias de busca nestes poderosos serviços de busca utilizando-se dos operadores booleanos. Nos serviços de busca de outros países são mencionados 6 (seis), sendo o mais conhecido o Google. Nos metamecanismos de busca de outros países são mencionados 3 (três), tais como o Dogpile, o Metacrawler e o Yippy. Neste mesmo segmento no Brasil são apresentados 5 (cinco): Achei, Aonde?, Bing (páginas brasileiras), Google Brasil e Yahoo! Brasil. Nos mecanismos de busca em redes sociais são relatados pelo autor: Facebook, Youtube, Twitter entre outros. São apresentados os procedimentos de como avaliar os mecanismos de busca, e o autor cita ainda 6 (seis) obras para a realização de leituras complementares. 
A obra inclui um índice de recuperação de todas as informações tratadas nesta obra, na mesma ordem alfabética, assuntos, nomes de pessoas e instituições, títulos de publicações, bases de dados e sítios na internet.

Ao adotar, para este livro, o mesmo título utilizado pela bibliotecária argentina (Josefa Emilia Sabor) em 1957, o autor espera que seu livro alcance a mesma utilidade que teve o "Manual de fuentes de información", elaborado por Sabor, possibilitando assim homenagear à ilustre colega argentina.

Destinado aos profissionais e estudantes da área da Ciência da Informação, este livro constitui no Brasil, uma primorosa obra, onde se reconhece o esforço do autor para ampliar a definição e conceitos de fontes de informação utilizadas muitas vezes pelo público da área da biblioteconomia, arquivologia e áreas pertinentes da Ciência da Informação. O livro além de sugerir leituras complementares, contribui ao aprofundamento e conhecimento das fontes de informação.

\section{REFERÊNCIA}

CUNHA, Murilo Bastos da. Manual de fontes de informação. Brasília, DF: Briquet de Lemos, 2010. 182p. ISBN 9788585637422.

\section{Como citar esta resenha:}

SANTOS, Gildenir Carolino. Resenha: Manual de fontes de informação. Rev. digit. bibliotecon. cienc. inf., Campinas, SP, v.11, n.1, p.164-170, jan./abr. 2013. ISSN 1678-765X. Disponivel em: <http://www.sbu.unicamp.br/seer/ojs/index.php>. 